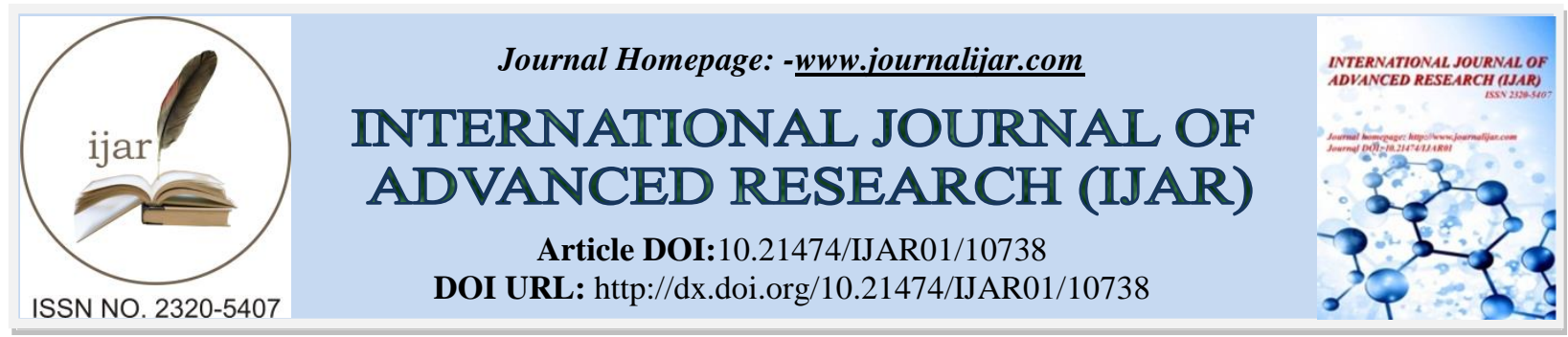

RESEARCH ARTICLE

\title{
A SMART SEMI-AUTONOMOUS FIRE EXTINGUISH QUADCOPTER: FUTURE OF BANGLADESH
}

\begin{abstract}
Abhijit Pathak, Abrar Hossain Tasin, Ayesha Akther Esho, Ashibur Rahman Munna and Tahia Chowdhury Department of Computer Science and Engineering, BGC Trust University Bangladesh, Chandanaish-4381, Chattogram, Bangladesh.
\end{abstract}

\section{Manuscript Info}

Manuscript History

Received: 05 February 2020

Final Accepted: 07 March 2020

Published: April 2020

Key words:-

Fire Fighter, Quadcopter, UAV, Fire Extinguisher, AFO Ball, Flight Controller

\section{Abstract}

A fire has been one of the key problems that have not yet been resolved despite technological progress. The most critical thing related to fires was human casualties. As stopping the fire from happening might not be feasible, it would be better to reduce its effects in terms of human casualties. A smart semi-autonomous fire extinguish quadcopter can manage difficult and dangerous tasks and its efficient performances enable it to be used in fire-related problems, such as reaching and exploring catastrophic zones. Therefore, an enclosed fire resistant unmanned aerial vehicle is built which allows victims to be searched and located in a minimum of time. The UAV is intended to operate while holding a fire extinguisher. Cameras are mounted on the UAV, so that the UAV controller can monitor the area. The above way, firemen's protection is guaranteed, because they actually know where to go. The adverse consequences of fire breakouts or fire on buildings or elsewhere present a significant danger to our lives. These incidents include the loss of property and life. Quadcopters actually can do any things that humans will never do. Quadcopters will serve as firefighters at this time. Quadcopters are much more likely to extinguish the fire as quickly as possible as the firefighters. We introduced an idea of how to use quadcopter for high precision fire detection and extinguishing. Our main focus is how to quickly extinguish the fire and at least avoid the fire from spreading by using quadcopter as well as how people can be rescued from the smoke of the fire, because of the smoke of the fire, people can't breathe, causing death. We are considering a new approach for fire detection and control, using improving techniques. Thus, the negative effect of fires can be greatly minimized by using Unmanned Ariel Vehicles (UAV) such as a quadcopter, which patrol firethreatening areas continuously. It will help in identifying and safeguarding vulnerable people caught in the fire.

Copy Right, IJAR, 2020,. All rights reserved.

\section{Introduction:-}

Bangladesh is a small developing nation with an overpopulation. Bangladesh's total land area is $130.170 \mathrm{square}-\mathrm{km}$. Bangladesh's total population as of Monday, March 16, 2020 is 164,206,353 based on World-meter elaboration of the latest UN statistics. In Bangladesh the population density is 1265 per km square. Bangladesh frequently faces numerous problems due to the overpopulation, one of which is a fire incident. Bangladesh has sustained extensive 
damage because of multiple fire incidents. In Bangladesh, there are several damaging forms of fire. In February 2010, fire at a garment factory in a suburb of Dhaka kills 21 employees and injures about 50 . And fire at a factory supplying multinational retailers in the same year kills 26 people and injures about 100 near Dhaka. In 2011, 365 people were killed and 1,385 injured as a result of a burn, the largest number of victims. Fire broke out in the Tazreen Fashion factory in Ashulia district at the outskirts of Dhaka, Bangladesh, on November 24, 2012. Throughout the history of the nation at least 117 people have been confirmed dead in the fire and more than 200 have been injured. At least 1.136 people have been killed and hundreds wounded in an 8-story factory, as the worst industrial accident ever in Bangladesh. In 2014, 70 individuals were killed and 210 injured due to burning. As far as financial loss is concerned, 2015 was the deadliest year, with an estimated loss of Tk 850, 68 persons have been killed and 216 wounded. There have been 16,857 fire accidents all over the country in which 152 people were killed and 247 injuries suffered, while a huge fire that erupted in a packaging plant killed at least 23 people in 2016. Bangladesh endured around 240 core 43 lake in the same year. According to the Fire Service and Civil Defense, 18,105 firefighters were killed in 2017 with 45 dead and 269 wounded. The loss was approximately 35 core 41 lakes this year. Thirteen civilians were killed and 664 wounded in 2018. In 2019, there were 81 deaths and 114 injuries caused by fire in Dhaka. Two people died in a fire in a Chittagong colony while one was severely burnt. In a further incident, three people were killed and five others were injured when a fire broke out in the garage in a five-story house on the ground floor. As the result of a burn in March 2020, at least 200 shanties in the slum of Rupnagar in the city of Mirpur were demolished. The fire was extinguished by 25 firefighters nearly for three hours. By March of this year twenty people were killed; about fifteen others were seriously wounded by fire. Despite of the fire accidents, most people lose their beloveds, losing their homes. Furthermore, in numerous industrial factories our economic system suffered significant losses due to burning. The fire extinguisher drone could also be operated as quickly as possible, if such fire losses had been minimized by fire incidents. In this way, the risk of firefighters would be every in their lives. We are discussing a highly effective quadcopter used in burning areas and this drone we will use Artificial Intelligence, thermal picture, solar panel, TEG, fire extinguishing ball AFO, fire extinguishing tank, poly-crystalline fiber to increase the accuracy of its fire extinguishers. The aims of this project are as follows:

1. Reduce fire losses for civilians.

2. The place in every fire of human survivors.

3. Defense of people stuck in fire blocks.

4. Increase the safety of firefighters and rescue teams.

5. Raising firefighters' awareness of the value of using modern rescue technologies.

The UAV will have the following characteristics in order to meet the previously stated targets:

1. Sensitizing the value of using emerging tools for recovery operations for firefighters.

2. Be low in sizes (storage buildings) for indoor use.

3. Take a fire extinguisher with a specific weight.

4. Has an easy-to-use control system.

5. Sending a minimal delay live stream.

6. Smoke control.

7. Equipped with cooling system.

8. A collision avoidance device must be fitted.

Table 1:- Summary of Fire Accidents in Bangladesh.

\begin{tabular}{|c|c|c|c|c|}
\hline \multicolumn{7}{|c|}{ Deaths, Injuries and Damages (Last 8 Years) } \\
\hline Year & Accidents & Injuries & Deaths & Damage (\$) \\
\hline 2013 & 78095 & 100 & 1136 & 1500crore \\
\hline 2014 & 17830 & 210 & 70 & 950 crore \\
\hline 2015 & 17488 & 216 & 68 & $850 \mathrm{crore}$ \\
\hline 2016 & 16857 & 247 & 152 & 240 crore, 43 lacs \\
\hline 2017 & 18105 & 269 & 45 & 35 crore, 41 lacs \\
\hline 2018 & 19642 & 664 & 13 & 320 crore \\
\hline 2019 & 24,074 & 586 & 185 & 330crore \\
\hline 2020 (March, 20) & 3 & 20 & 15 & 120crore \\
\hline Total & $\mathbf{= 1 9 2 0 9 4}$ & $\mathbf{= 2 3 1 2}$ & $\mathbf{= 1 6 8 4}$ & $\mathbf{= 4 3 4 5}$ crore, 84 lacs \\
\hline
\end{tabular}


Literature Review:

\begin{tabular}{|c|c|c|}
\hline Related Works & Description & Limitation \\
\hline $\begin{array}{l}\text { "Use of Fire-Extinguishing } \\
\text { Balls for a Conceptual System } \\
\text { of Drone-Assisted Wildfire } \\
\text { Fighting" } \\
\text { BurchanAydin, EmreSelvi and } \\
\text { Michael J Starek }\end{array}$ & $\begin{array}{l}\text { The paper addresses the possible use as } \\
\text { part of a proposed network of drone and } \\
\text { remote sensing technology for the } \\
\text { replacement of conventional firefighting } \\
\text { processes (2) the contact between the } \\
\text { UAS and the UAS scouting to create } \\
\text { and expand communications canals } \\
\text { between the UAS scouts and the } \\
\text { firefighting USA, and (3) firefighting } \\
\text { the US autonomously flying to the } \\
\text { dropping points (3) a scouting } \\
\text { unmanned aircraft system (UAS). }\end{array}$ & $\begin{array}{l}\text { The precision can be lower due to } \\
\text { indirect remote sensing measurements. } \\
\text { The goal cannot be visible at times } \\
\text { (e.g. clouds). The definition of } \\
\text { creativity calls for a certain degree of } \\
\text { ability. Needs a ground (field) cross- } \\
\text { verification for survey results. } \\
\text { Confusion can be caused by data from } \\
\text { different sources. }\end{array}$ \\
\hline $\begin{array}{l}\text { "Automatic CO2 Extinguisher } \\
\text { Fire Fighting Drone" } \\
\text { EtharaBalaVyshnavi, } \\
\text { Amareswari Ambati, Gorantla } \\
\text { Chamundeswari } \\
\text { GarreVineetha }\end{array}$ & $\begin{array}{l}\text { The quadcopters, commonly referred to } \\
\text { as Unmanned Aerial Vehicles (UAV), } \\
\text { are an air vehicle that fly independently } \\
\text { through a remote-control device. They } \\
\text { are called rotor crafts, since they } \\
\text { operate with a series of twisted airfoils } \\
\text { with a rotating chord. Because of many } \\
\text { reasons, such as the simple build and } \\
\text { assembled difficulty, quadcopter is } \\
\text { becoming more overly used. }\end{array}$ & $\begin{array}{l}\text { It operates after a certain distance since } \\
\text { it runs by wireless remote control. }\end{array}$ \\
\hline $\begin{array}{l}\text { "Development of FAROS } \\
\text { (fire-proof drone) using an } \\
\text { aramid fiber armor and air } \\
\text { buffer layer" } \\
\text { W.C. Myeong, K.Y. Jung and } \\
\text { H. Myung }\end{array}$ & $\begin{array}{l}\text { Due to the advancement of construction } \\
\text { technology and other economic factors, } \\
\text { high-rise buildings and large complex } \\
\text { structures are now rising rapidly. As the } \\
\text { city is heavily populated, a fire incident } \\
\text { may be dangerous so it is very } \\
\text { important to access the situation at an } \\
\text { early stage to contain fire so evacuate } \\
\text { the residents. This provides the } \\
\text { advantages of an air robot platform due } \\
\text { to its ability to access the hard to reach } \\
\text { location. For most cases, however, their } \\
\text { basic components, such as electronics, } \\
\text { are exposed directly to the air to } \\
\text { minimize its own weight and cooling } \\
\text { impact. }\end{array}$ & $\begin{array}{l}\text { The fiber will last up to } 500^{\circ} \text { at high } \\
\text { temperatures. This aramid fiber will } \\
\text { stop working, allowing the drone to } \\
\text { burn if the temperature of the fire } \\
\text { reaches above } 500^{\circ} \text {. }\end{array}$ \\
\hline $\begin{array}{l}\text { "Early Forest Fire Detection } \\
\text { Using Drones and Artificial } \\
\text { Intelligence" } \\
\text { DiyanaKinaneva, Georgi } \\
\text { Hristov, Jordan Raychev and } \\
\text { PlamenZahariev }\end{array}$ & $\begin{array}{l}\text { In many countries around the world, } \\
\text { forest and urban fires have also been } \\
\text { severe problems. There are actually a } \\
\text { variety of forest fire fighting solutions. } \\
\text { Such approaches are mainly designed to } \\
\text { minimize fire damage using early } \\
\text { warning methods. In this paper, we } \\
\text { address a new fire detection and control } \\
\text { approach that uses modern } \\
\text { technologies. }\end{array}$ & $\begin{array}{l}\text { They do not have a solution if the } \\
\text { battery charge of the drone goes down. }\end{array}$ \\
\hline $\begin{array}{l}\text { Proposed System } \\
\text { A Smart Semi-Autonomous } \\
\text { Fire Extinguish Quadcopter: } \\
\text { Future of Bangladesh }\end{array}$ & \multicolumn{2}{|c|}{$\begin{array}{l}\text { The problem is going to be solved by understanding the limitation of previous fire } \\
\text { extinguishing systems because a web server is required for the data transmission. } \\
\text { So, the quadcopter is easily controlled. Before the fire extinguishing system is } \\
\text { deployed, we are working on our project to create and control. In view of the } \\
\text { conditions in Bangladesh, we suggested a quadcopter system to achieve our } \\
\text { objectives. }\end{array}$} \\
\hline
\end{tabular}




\section{Concept of Quadcopter:}

Quadcopter is an Aircraft Unmanned Vehicles (UAV). UAV may typically be defined as an airborne device, without a pilot on-board, used or planned to be used for flight. These devices are also referred to as drones designed to operate independently, which a control operator may operate remotely from any location in the world through the Internet. This can in many cases lead, particularly for industrial applications, to high maintenance and deployment costs. Our quadcopter is used to sense fire, extinguish fire, and save lives with the highest precision as soon as possible. Our quadcopter is fitted with four trust propellers, either in a cross configuration or in a plus. This is a significant benefit as it eliminates landing platform requirements for the quadcopter to be taken out and landed upright. This also allows the quadcopter to float with great stability. Nevertheless, the stability of the quadcopter prevents it from crashing due to strong wind or weight. The quadcopter can float at a constant height with its roller and pitch angles balanced by the propeller. Quadcopters are using 2 sets of identical fixed propellers, 2 in clockwise $(\mathrm{CW})$ and 2 in counterclockwise. The front and rear propellers rotate counterclockwise, while the left and right propellers rotate clockwise. The opposite pairs arrangement passes the need for a threshold rotor of the same rpm for both propellers.

\section{Mechanism of Quadcopter Movement:}

The quadcopter can be represented as a small vehicle with four rotor propellers on the cross frame. The goal is to monitor the movement in the vehicle using fixed pitch rotors. The speeds are independent of these four rotors. The vehicle can easily be controlled by the independent pitch, roll and yaw attitude.

\section{Motion system for take-off and landing:}

Start off is a quadcopter movement which lifts from the ground to the hover, which reverses the start position. The motion of a start (landing) is controlled simultaneously with an increase (declining) of four rotors, indicating that the vertical motion is changed.

\section{Static or floating place:}

Two rotors rotate in clock-sided and counter-clockwise respectively with the same speed in the floating or static positions of the quadcopter. The total sum of a reaction torque is zero and thus makes a quadcopter in the hovers by two rotors rotating in a clockwise and opposite clockwise direction.

Four propellers are used by our quadcopter, each with its own motor and electronic speed control. We can calculate the angle of the quadcopter in $\mathrm{X}, \mathrm{Y}$ and $\mathrm{Z}$ using accelerometer, changing the RPM of each motor to self-stabilize. As a result of the counter-turning engines that give a net moment zero to the middle of the quadcopter, the quadcopter platform provides stability. In recent years, the different protection systems have increased the use of drones. This paper mainly refers to a small $\mathrm{X}$-shape quadcopter design and implementation. Using this concept to correctly control the lace, pitch, and roll of quadcopter (rpm as a function of the voltage given to the motor) on-motor. Temporary and rolling control can be achieved by adjusting the speed of the respective engines, while a delicate combination of all four engine functions is required to adjust the momentary forces applied to the quadcopter. In recent years, the different protection systems have increased the use of drones. In general, this article refers to a mini $\mathrm{X}$-shape Quadcopter concept and implementation.

\section{Block Diagram:}

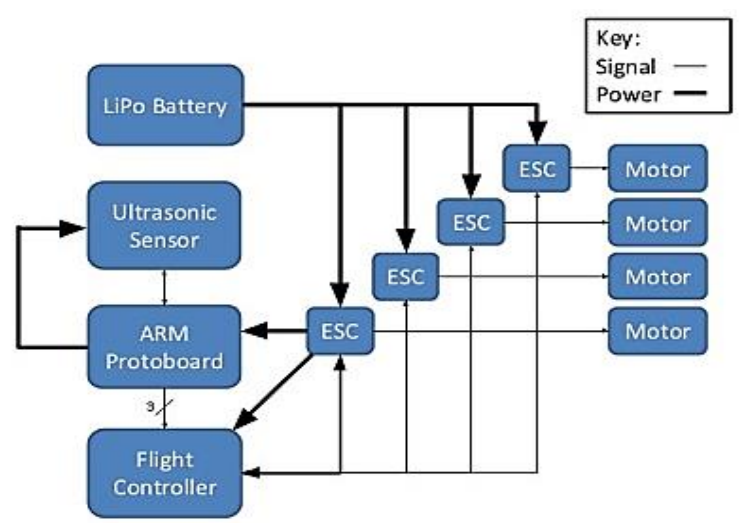

Fig. 1:- A Top-level Design of Quadcopter. 


\section{System Architecture:}

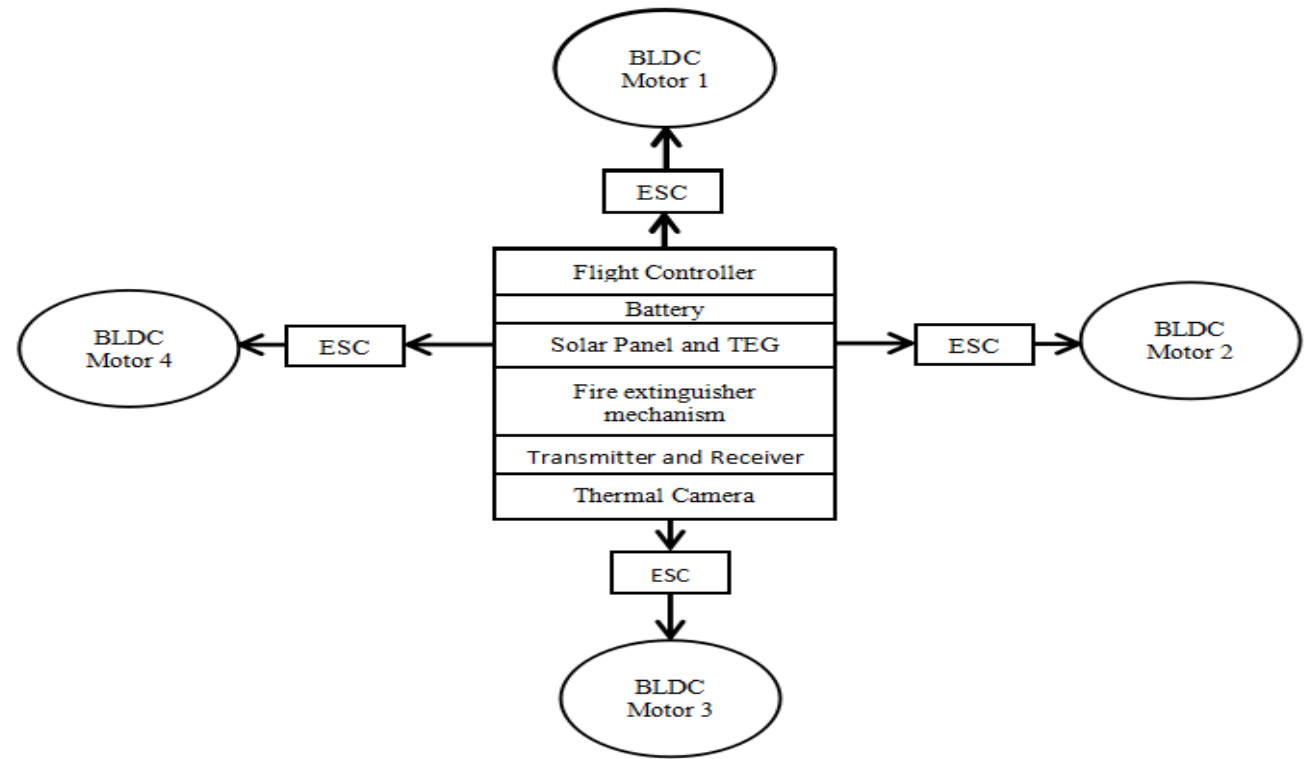

Fig. 2:- System Architecture.

\section{Technical Control of Aircraft:}

First of all, it is necessary to understand the terminology of every design. The flight's movement mechanism includes three fundamental motions, which must be controlled continuously and normalized ( 0 degree). They are:

Throttle: Throttle controls the vertical up and down motion of the drone.

Roll: Roll is a side-by-side rotation (up-down wings).

Pitch: Pitch is the front and tail end movement. It therefore pushes the front end higher or vice versa than the tail end. It tests whether or not the quad goes forward.

Yaw: Yaw is the direction the quad is facing.

Each rotor (brush-less engine) in quadcopter $\mathrm{X}$ is located at four corners of the ' $\mathrm{X}$ ' structure, generating a certain thrust and torque in its center of spinning. The rotation directions at $1 \& 3$ are in a clockwise direction, $2 \& 4$ in a clockwise direction. Not every four-rotor propeller is the same.
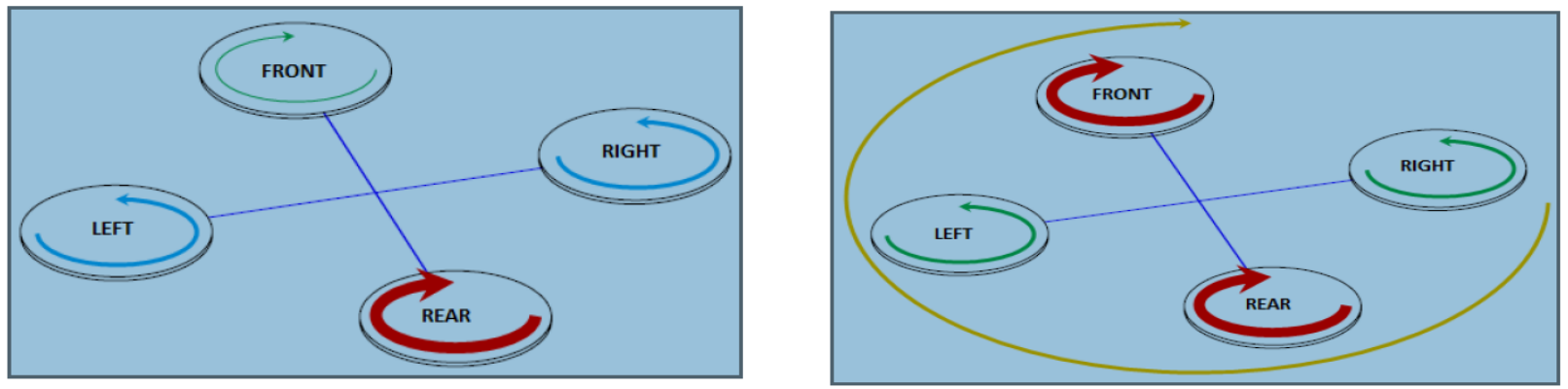

Figure 3:- Illustration of Throttle, Pitch, Roll and Yaw.

Two propellers out of four are pushers, while the others are puller tips. That if the entire propeller rotates in the same direction, the net torque may be zero.

Such dynamic parameters were usually employed in the orientation of the aircraft: grip, yaw, pitch and roll. The four propeller speeds together can be increased or decreased by vertical motion. Figure 3 shows that all possible quadcopter motions depend on the propeller rotational speed. 


\section{System Flowchart:}

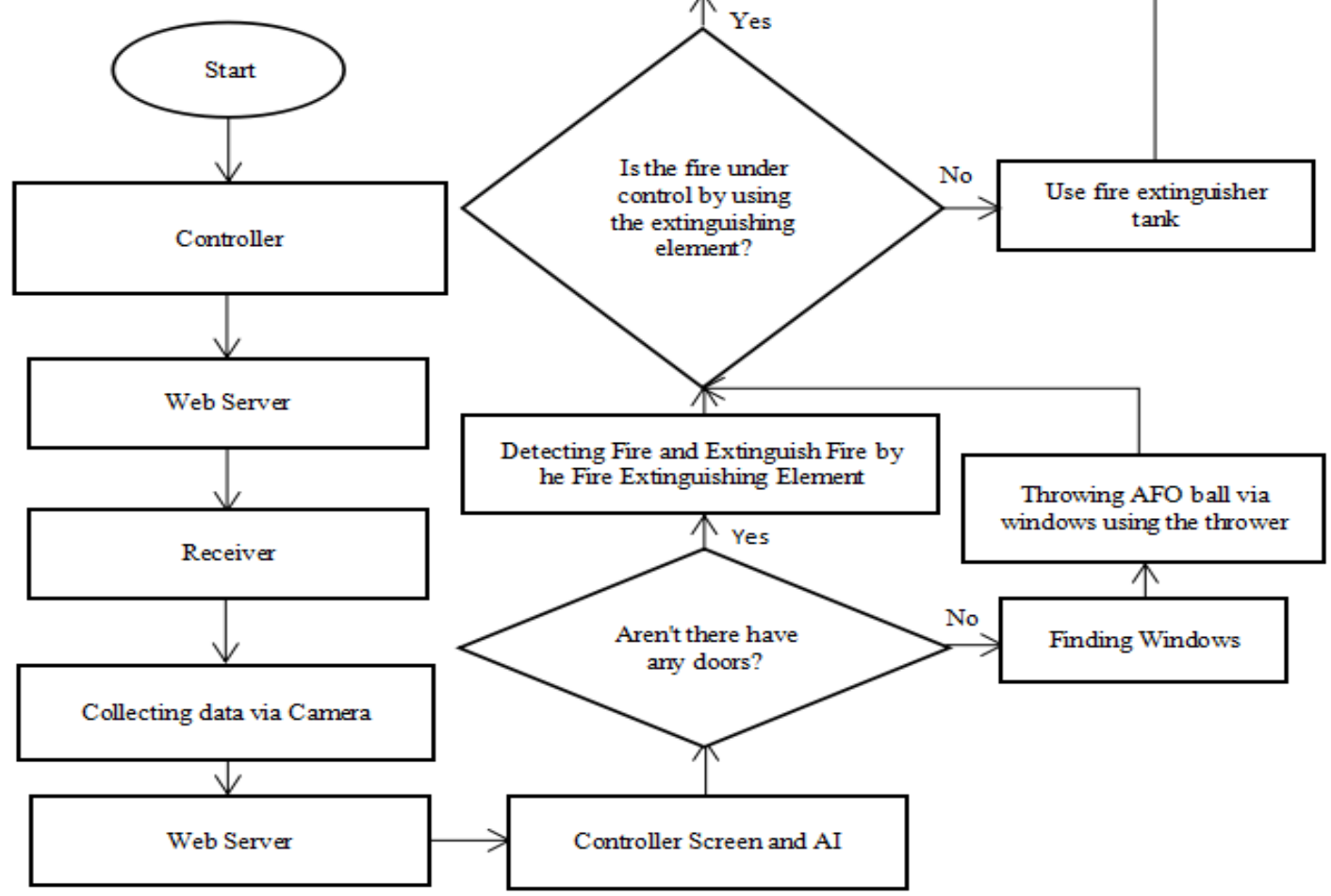

Fig. 4:- System Flowchart.

Frame Design:

Forward Motion

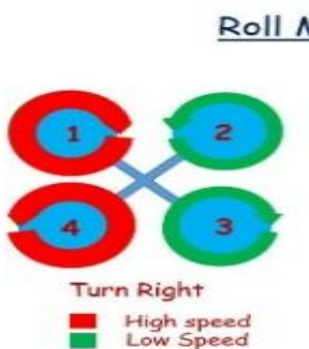

Roll Monitoring

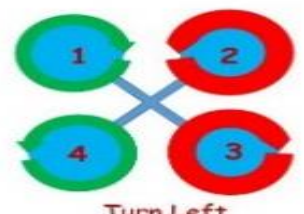

- High speed

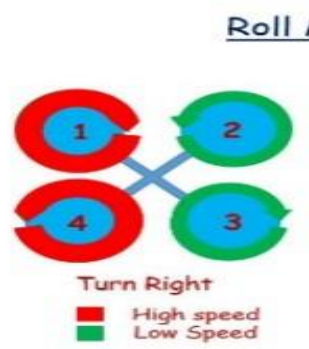

Roll Monitoring
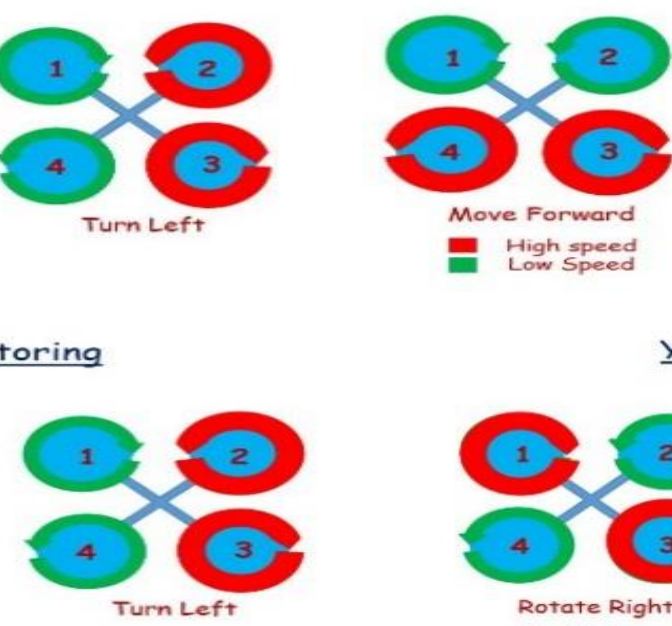

Move Forward

- High speed

Pitch Monitoring

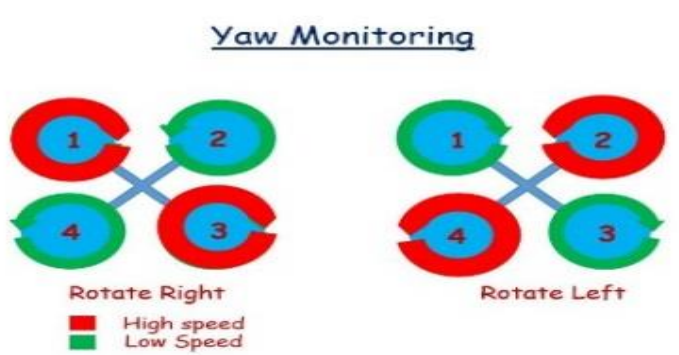

Fig. 5:- Left Motion \& Right Motion.

Forward (backward) motion is control by increasing (decreasing) speed of rear (front) rotor. Decreasing (increasing) rear (front) rotor speed simultaneously will affect the pitch angle of the quadcopter. The forward and backward motions of quadcopter are represented in figure below. 


\section{Left and Right Motion}

It can control the left and right movement by adjusting the quadcopter logout angle. By rising (dismissing) the angle of the rotor in the counterclockwise direction the speed of the Yaw rotor can be controlled while the clockwise speed is decreasing. Figure 6 reveals quadcopter's right and left step.

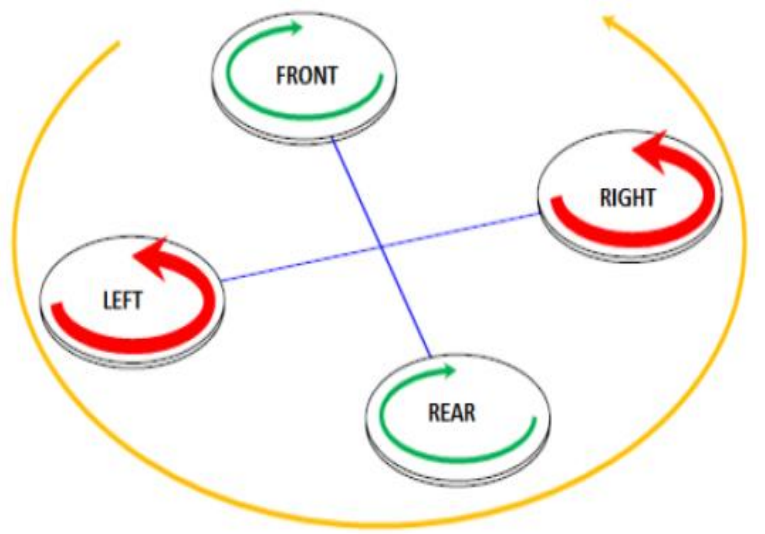

Fig. 6:- Left and Right Motion.

\section{CC3D Flight Controller}

This remarkable flight controller that is shipped from US warehouse has been created by the Open Pilot group. Inside an esteemed and mercantile facility in the 'pick and place' category, Open Pilot rendered this CC3D with intimate partnership, which is designed with the best elements. This CC3D gives a crackling sensation while flying Ti copter, quads, hexes, octocopter, and even fixed wing aircraft.

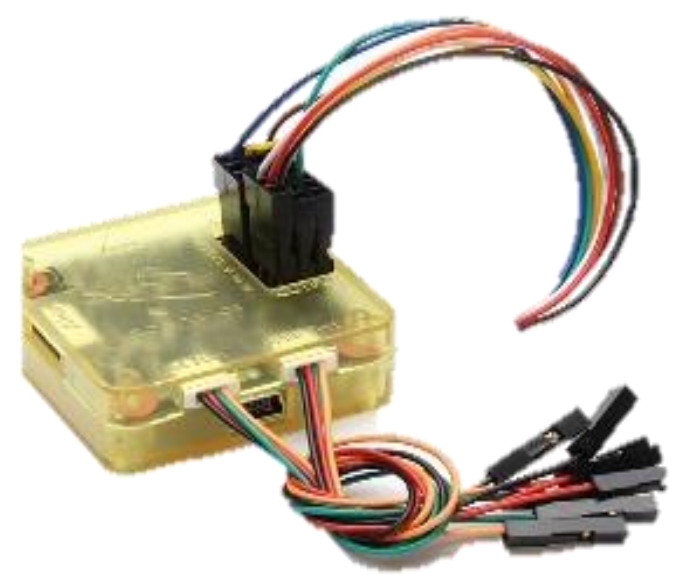

Fig. 7:- CC3D Flight Controller.

\section{Radio link AT9}

Different types of remote controller used for common aircraft models such as Quadcopters, Helicopters, Hexacopters, and Octo-copters etc. Radio connection AT9 from those is the easiest and cheapest remote controller for 9 channels. For beginners it is recommended because it is easy to use and not that complicated. Radio connect AT9 equipped with $240 * 320$ pixels, including great equipment, and has a 2.8-inch clear screen. Answer takes a little bit of time, nearly just 3ms (millisecond). AT9 radio link comes with anti-interference DSSS technology. 


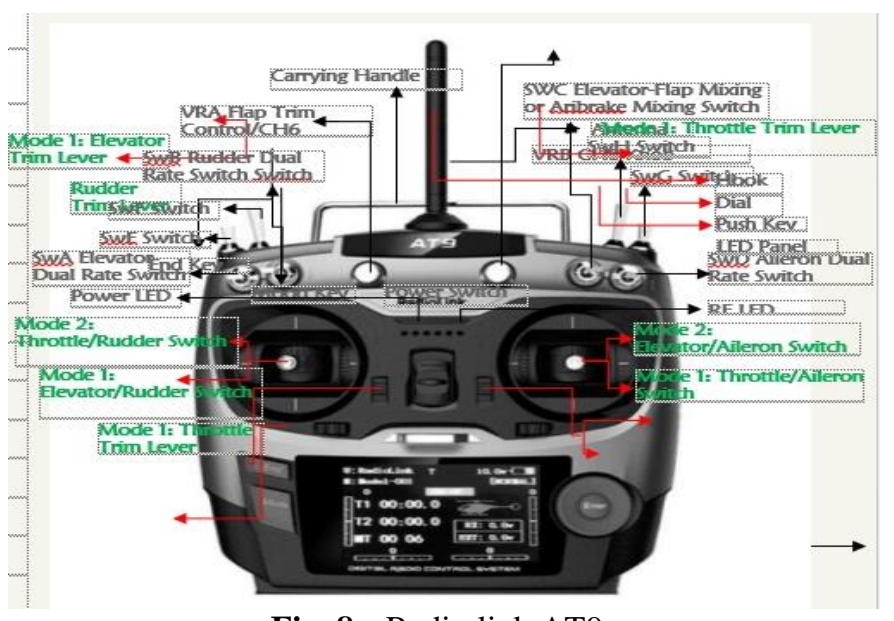

Fig. 8:- Radio link AT9.

\section{Features:}

1. Full types and functions

2. Fast throttle response

3. Long distance stable operating

4. Date telemetry

5. Vibration alarm

6. S-BUS supported

7. Firstcontrol system containing menu ofaircraft

8. Precision 4096

9. Navigation menu

10. USB updating

11. Mini receiver

12. Programmable mix control

13. Humanized switch positioning

\section{Hardware Design:}

Design Procedure - Components

Li-Po Battery [Tiger 3 cell $4500 \mathrm{mAh}$ ]

This is the source of power for the whole quadcopter. The $11.1 \mathrm{~V}$ battery runs directly to the ESCs. The ESCs divert power to the engines, the flight controller, and the ARM microcontroller.

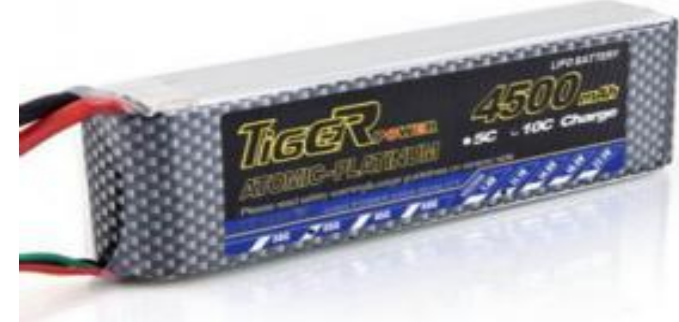

Fig. 9:- Li-Po Battery.

Electronic Speed Controllers (ESC) [Mystery Fire Dragon 30A Brush-less ESC] Such controls supply motors with power by moving energy from the aircraft controller. The inputs are the control signals from the flight controller and the 11.1-12.4V signals from the Li-Po battery. Outputs include a 5V Battery Removal Circuit (BEC) power supply that can power a flight controller or ARM microcontroller, and up to $220 \mathrm{~W}$ of engine power. They are rated to power up to $20 \mathrm{~A}$ from the Li-Po battery. The amount of electrical energy supplied to the engines shall be based on the input signals of the flight controller. 


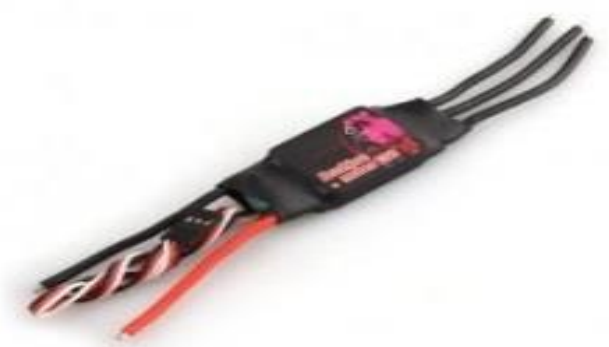

Fig. 10:- Mystery Fire Dragon 30A Brush-less ESC.

Motors [XA2212-1400kv Out-runner Brush-less Motor] The drives are driving the propellers using 220W from electronic speed controllers (ESCs). Speed tuning is obtained through Clean-flight software by PID tuning of ESCs.

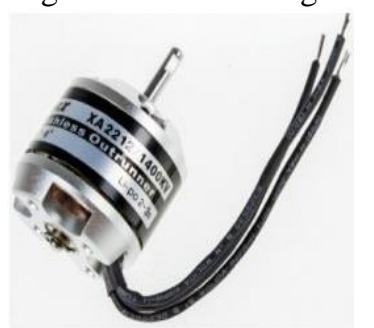

Fig. 11:- XA2212-1400kv Out-runner Brush-less Motor.

\section{Propellers:}

It has four drives and two $\mathrm{CW}$ propellers that refer to a clockwise rotation and two additional $\mathrm{CCW}$ drives that refer to a counter clockwise rotation.

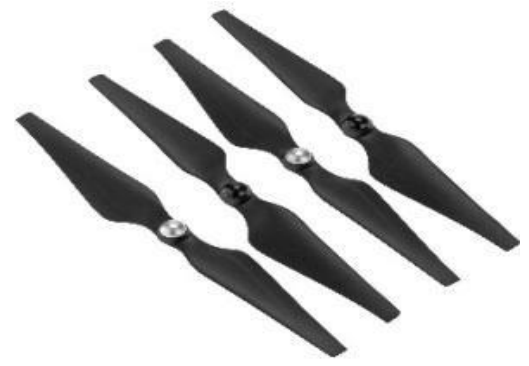

Fig. 12:- Propeller.

\section{Camera Peripherals}

In this drone we are using the Thermal Imaging Camera. It detects heat variations in its field of vision. However, there is no light expected. The concept of thermography is perfect for firefighters because it can be seen by smoke. The key advantages of using a thermal imaging camera are that moving objects can be filmed in real time and used for night vision purposes. In the long wavelength of visible light, thermal imagery cameras detect. Dust, smoke and other light sources do not interfere with how an image/video can be recorded. For high-efficiency use of XC300 thermal camera. Feature of this camera:

1. Measuring range $\left({ }^{\circ} \mathrm{C}\right) \mathrm{min} / \max :-20-600$.

2. Accuracy max.: $+/-2{ }^{\circ} \mathrm{C}$ or $+/-2 \%$ of the current reading.

3. Detector resolution: $384 \times 288$

4. Spectrum range: 8-14 um.

5. Frame refresh rate: $50 / 60 \mathrm{~Hz}$.

6. Geometric resolution: $1.1 \mathrm{~m} \mathrm{rad}$

7. Standard lens // Image performance radiometric: $24^{\circ} \times 18^{\circ}$

8. Minimum focus distance: $0.15 \mathrm{~m}$

9. Field of view (FOV): $24 \times 18^{\circ}$

10. Operating time: up to 8 hours.

11. Storage media: internal 16GB (32GB optional) 
12. Operation - $\min / \max$. Temperature $\left({ }^{\circ} \mathrm{C}\right):-20-50$

13. Bearings - min/max. Temperature $\left({ }^{\circ} \mathrm{C}\right):-40-70$.

14. Humidity min./max. (non-condensing) (\%): 10-95

15. Protection class: IP54 IEC 529

16. Wavelength $(\mu \mathrm{m}): 635$.

17. Dimensions (L x W x H): $130 \times 125 \times 250 \mathrm{~mm}$

18. Weight: $0.85 \mathrm{~kg}$

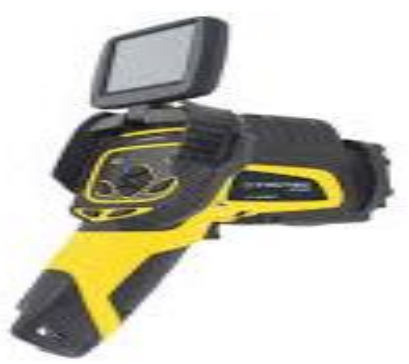

Fig. 13:- XC300 Thermal Camera.

\section{Solar Panel:}

In any case, we use the solar panel to charge the battery. A thermoelectric device called a See beck generator, which transforms heat directly into electricity by means of an event called the See beck effect, is also used. They do use the TEG device. This can also be used to charge the battery from the fire gas.
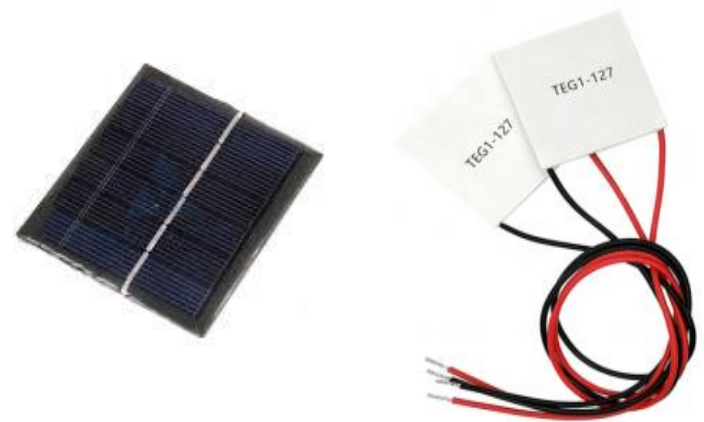

Fig. 14:- Solar Panel and TEG.

\section{Poly-crystalline Fiber:}

In order to protect it from fire damage, the entire quadcopter must contain poly-crystalline fiber. This can survive up to 1700 degrees Celsius temperatures. PCWs are used in the most demanding thermal and mechanical applications with examples in the ceramic, rubber, aerospace and automotive industries.

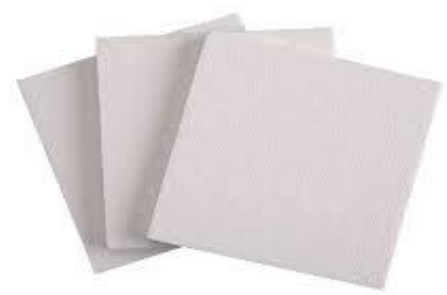

Fig. 15:- Poly-crystalline Fiber Board.

\section{Nozzle:}

Within this quadcopter a nozzle is used to remove gas for extinguishing fuel. 


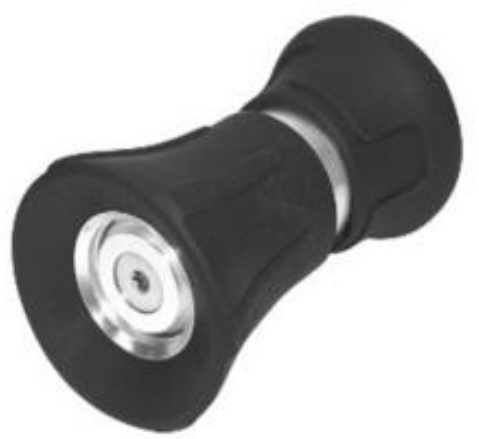

Fig. 16:- Nozzle.

\section{AFO Fire Extinguisher Ball}

The AFO Fire Extinguisher Ball is a 7 "diameter spherical device with all the non- fire suppressors available inside it and ready when appropriate to be deployed. It is intended to trigger chemicals and distribute them into contact with the fire within five seconds, so that you can easily throw them in the middle of the blaze like a basketball or roll them into the field. This would disperse the chemicals much further over a distance of up to 107 square feet so that a single burn can be done on itself.

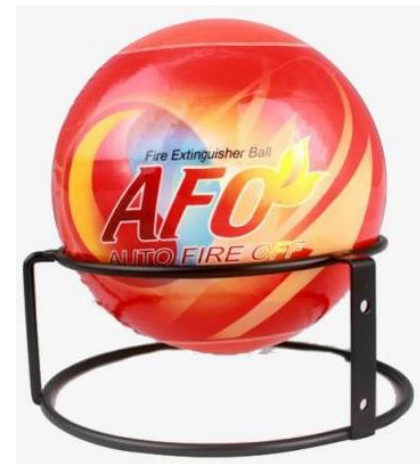

Fig. 17:- AFO Fire Extinguisher Ball.

\section{Software Design:}

It's actually a ground control station and used it the different type of drone configuration. It's refers how much value (speed, voltage, other power supply) are fixed by default. X-shape quadcopter are 4 motor are setup by Open-Pilot GCS.

\section{Configurations and Calibrations:}

First let us discuss the balancing control techniques in different quadcopter modes. Quadcopter can fly in (+) configuration and $(\mathrm{X})$ configuration. The only difference between these modes is where the front of the quad is. The following diagram illustrates the difference.

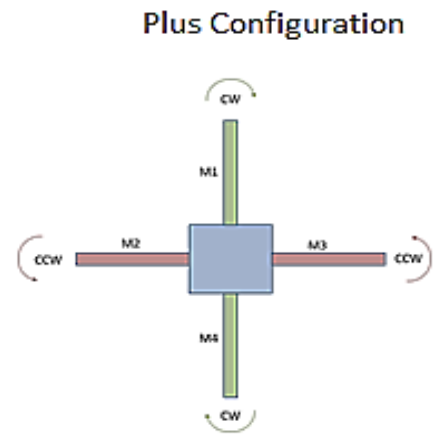

$$
\text { X Configuration }
$$

Fig. 18:- Quadcopter Configuration "X \& Plus". 
Plus (+) Configuration Control

In this configuration the control as follows:

Pitch Control

$\mathrm{M} 1$ = M1 + RX(Elevator $)$;

M4 = M4 - RX(Elevator);

Roll Control

$\mathrm{M} 2=\mathrm{M} 2+\mathrm{RX}$ (Aileron);

M3 = M3 - RX(Aileron);

It is very easy to use and is available in any quadcopter program. There are of course some checks here and there to prevent engine stoppage or saturation. But the principle of flight is still as above. There is also a scaling factor used to evaluate the stick sensitivity, and a dividing factor that restricts the value range.

X Configuration Control

Pitch Control

$\mathrm{M} 1=\mathrm{M} 1+\mathrm{RX}$ (Elevator) $/ 2$;

$\mathrm{M} 3=\mathrm{M} 3+\mathrm{RX}$ (Elevator) $/ 2$;

$\mathrm{M} 4=\mathrm{M} 4$ - RX(Elevator) /2;

$\mathrm{M} 2=\mathrm{M} 2-\mathrm{RX}$ (Elevator) $/ 2$;

Roll Control

$\mathrm{M} 1=\mathrm{M} 1+\mathrm{RX}$ (Aileron) $/ 2$;

$\mathrm{M} 2=\mathrm{M} 2+\mathrm{RX}$ (Aileron) $/ 2$;

M3 = M3 - RX (Aileron) /2;

M4 = M4 - RX(Aileron) /2;

As we see it, we believe only that M1 \& M3 act as a single virtual engine together on the front, and that M2 \& M4 operate together as a virtual motor on the back. It's the same logic, besides that.

In the PLUS form, the same criteria and element are also applied here. The prototype of the developing project is shown below:

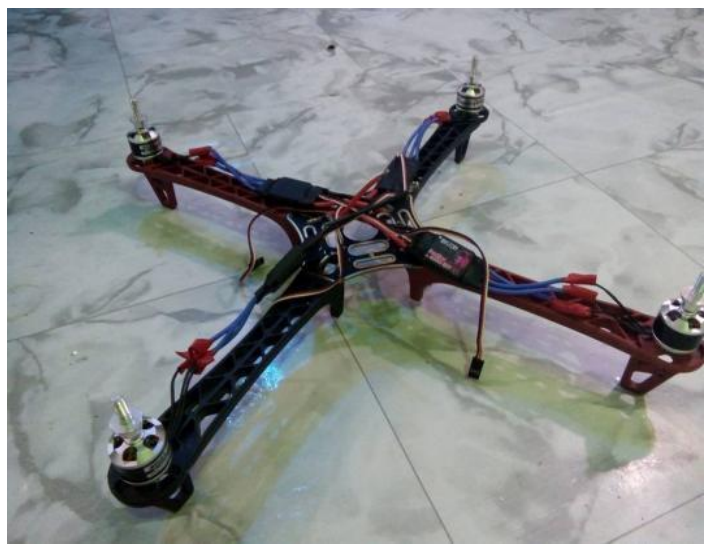

Fig. 19:- Prototype of the Proposed System.

\section{Stabilization System:}

Now let us see the stabilization system. The idea is simple, if the quad is falling to the right then speed up the right motor and slow the left one with the same amount and vice-versa. Also, if the quadcopter is falling down from the front arm then speed up the M1 motor and slow down M4. The rule is written as follows.

M1 = M1 + Pitch Amount * Pitch Gain

M4 = M4 - Pitch Amount * Pitch Gain

M2 = M2 + Roll Amount $*$ Roll Gain

M3 = M3 - Roll Amount * Roll Gain 
This is the basic rule that should be found in all quadcopter programs. The main difference between the different firmware approaches is how to calculate Pitch Amount and Roll Amount. The Gain factor is used to determine the sensitivity.

Flight Time

The UAV shall be measured as follows for optimum flight time:

$$
\text { Maximum Flight Time (min.) }=\frac{\text { Battery Storage Amp Rating }(m A h) * 60}{\text { Current Draw of UAV }(A m p s)}
$$

The battery has a capacity of $22000 \mathrm{mAh}$. That is to say, the battery has an amp / minute (22000/1000) *60. The UAV uses an average of about 30 amps after many trips, as the transmitter is observed. The flight time for the UAV therefore amounts to $1320 / 30=44$ minutes.

Whereas the required time of flight is determined as follows:

Recommended Flight Time ( $\mathrm{min}$.)

$=$ Maximum Flight Time (min.) $x$ Safety Factor

Where, 0.4 to 0.7 is the protection factor. The estimated flight time is therefore between 17.6 and 30.8 minutes.

Recommendations

Table 3 offers specifications for the prototype UAV to summarize the results of several tests performed.

Table 3:- UAV Recommendations

\begin{tabular}{|l|l|}
\hline Dimension & $101.6(\mathrm{~W}) \times 90.1(\mathrm{~L}) \times 30(\mathrm{H}) \mathrm{cm}$ \\
\hline UAV Weight & $6400 \mathrm{~g}$ \\
\hline Payload & $3700 \mathrm{~g}$ \\
\hline Operating Temperature & $\leq 1300 \mathrm{oC}$ \\
\hline Maximum Flight Time & 44 minutes \\
\hline Recommended Flight Time & 17.6 to 30.8 minutes \\
\hline
\end{tabular}

Mechanism of Extinction of Fire:

In this quadcopter we use fire removing tank and AFO fire removal ball for the extinction of flames. Firefighters strongly argued that a bigger extinguishing ball should be used and that, in the case of fires, a number of balls could be fired in the room. If the AFO ball is thrown into a fire, the building fire may be slowed down. The powder could be more spherical and more effective if the balls were thrown higher up. This made the work even more optimal. We're not using water to extinguish fire in this quadcopter because Firefighters commented that "... water damage is destructive compared to that, these balls won't do any harm to the buildings....". This made the job even easier. In this quadcopter we don't use the water to extinguish fire as Firefighters said ... water damage is damaging, compared with that these balls will do no harm to the buildings.... The area divided by three is a thumb rule to decide how much water a fire needs per minute. Our AFO balls can also be thrown into a broken window when a fire bursts in a closed space or if nobody can reach the house. This quadcopter has a thermal camera in particular. The thermal camera is used to carry a live thermal image of the fire to the fire scene; this will allow them to track fire tremendously as soon as it arrives on the scene. Our quadcopter has the potential to provide the suffering people with medical equipment and even food.

\section{Project Portfolio:}

1. Compared to the traditional method of sending a fireman to the building using a crane, this firefighting quadcopter has the potential to hit higher building in very less time.

2. The main advantage of using quadcopter is that it remains stable in the air throughout its function, due to its Vertical Take-off and Landing property (VTOL) which enables the quadcopter to travel in any direction. So, it can be quicker to hit.

3. This decreases the risk of a fireman as it can be worked from a long distance.

4. Reducing fire-related civil losses.

5. The quadcopter will extinguish the heavy-duty fire of a vehicle. 


\section{Conclusion:-}

Bangladesh is highly vulnerable to catastrophic disaster shaping the existing situation of fire protection in the industrial sector. From the findings evaluation and study, the safety assessments of fire hazards are inadequate in the industry. It has been found that much of the industry does not have enough resources to deal with fire catastrophes. Equipment such as an alert device, smoke alarm, fire resistance door, appropriate fire emergency exits, firefighters are available only for some sectors, but insufficient amounts are available. Besides, the lift and staircases of the most building were inadequate. To order to prevent the spread of fire, the fire barriers can be used for creating compartments in the cavity mounted horizontally and vertically between the covering and the internal wall. However, this device must be designed very well to operate effectively, and depending on the form and condition of the current walls, it is not always possible for retrofitting. The early fire detection system is still in development. Yet our quadcopter is too powerful to monitor the explosion, and the actual application has been debated. If they are caught in a mess or other problems, fire extinguishing department will easily monitor the quadcopter. They can monitor it from anywhere in Bangladesh and delete fire from the site, and the quadcopter is entitled to reload it. So, we think that our quadcopter is better positioned as soon as possible to extinguish the fuel. We have extensively studied and experimented with simulations and believe we are taking the right direction to meet the target. We also assume that we are using a correct, up-to-date approach. Good knowledge of the situation and controls will allow firefighters to save life and property effectively without injury or death. The statement also supports the notion of using software to boost the efficiency of command and control.

\section{References:-}

1. "Development of FAROS (fire-proof Quadcopter) using an aramid fiber armor and air buffer layer" DOI: 10.1109/URAI.2017.7992713

2. A paper on "Unmanned Aerial Systems in the Fire Service: Concepts and Issues" by Dr. Ronald T. Wakeham\& Dr. John C. Griffith

3. Aakash Sehrawat, Tanupriya Choudhury, Gaurav Raj, "Surveillance Quadcopter for Disaster Management and Military Security", International Conference on Computing, Communication and Automation (ICCCA2017), pp. 472- 473, 2017

4. Abinesh, Deepak, Chandraprakash.K, Gowtham.M, Ananthi. K "FIRE FIGHTING QUADCOPTER”, 2017, International Journal of innovative and Emerging Research in Engineering. Pg. 112-144

5. An article on "fire extinguishers" from explainstuff.com

6. An article on "Firefighting Quadcopter using $\mathrm{CO} 2$ ball extinguisher" by Yuvraj Akhade, Akash Kasar, AnujaHonrao, nehalGirme in IJIRCCE vol. 5, issue 2, February 2017

7. Anton Nakazawa, Bai Xiang Jin, "Quadcopter Video Surveillance UAV”, University of Victoria, 2013(approx.)

8. Aydin, B.; Selvi, E.; Tao, J.; Starek, M.J. Use of Fire-Extinguishing Balls for a Conceptual System of DroneAssisted Wildfire Fighting. Drones 2019, 3, 17

9. C. Yuan, Y. M. Zhang and Z. X. Liu, "A survey on technologies for automatic forest fire monitoring, detection, and fighting using unmanned aerial vehicles and remote sensing techniques", Canadian Journal of Forest Research, vol. 45, no. 7, pp. 783-792, 2015

10. Chen, Thou-Ho, Cheng-Liang Kao, and Sju-Mo Chang. "An intelligent real-time fire-detection method based on video processing." Security Technology, 2003. Proceedings. IEEE 37th Annual 2003 International Carnahan Conference on. IEEE, 2003

11. Elide Fire Extinguishing Ball. Available at online: http://www.elidefire.com/products.htm (accessed on 7 December 2017)

12. Final documentation on "design and fabrication of quadcopter" by rohitsai raj

13. Gaszczak, T. P. Breckon, and J. Han, "Real-time people and vehicle detection from uav imagery", in IS\&T/SPIE Electronic Imaging. International Society for Optics and Photonics, 2011, vol. 7878, no. 78780B

14. Herron, K.G.; Smith, H.C.J.; Silva, C.L. US Public Perspectives on Privacy, Security, and Unmanned Aircraft Systems; Technical Report; University of Oklahoma: Norman, OK, USA, 2014

15. J. Wang, Y. Zhang, J. Lu, and Y. Li, "Target detection and pedestrian recognition in infrared images", Journal of Computers, vol. 8, no. 4, pp. 1050-1057, 2013

16. Jason Moore, Aberdeen, MD(US) "UAV FIRE-FIGHTING SYSTEM", 2013 United states Patent Application Publication

17. Jian, Z., Yangwei, Y., "Brushless DC Motor Fundamental Application Node" MPS Module, 2014

18. LMAOLMRXVJR Martínez-of-God, "Multi-UAV Experiments: Application to Forest Fires", of Multiple Heterogeneous Unmanned Aerial Vehicles, Berlin Heidelberg, Springer, 2007, pp. 207-228 
19. Luis Merino, Fernando Caballero, J.R. Martínez-de Dios and AníbalOllero, "Cooperative Fire Detection using Unmanned Aerial Vehicle", Proceedings of the 2005 IEEE International Conference on Robotics and Automation Barcelona, Spain, April 2005, pp. 1884,2005

20. Martínez-de Dios J. R.; Merino, L.; Caballero, F.; Ollero, A. Automatic forest-fire measuring using ground stations and unmanned aerial systems. Sensors 2011, 11, 6328-6353

21. Pero Skorput, SadkoMandzuka, HrvojeVojvodic, "The Use of Unmanned Aerial Vehicles for Forest Fire Monitoring”, 58th International Symposium ELMAR-2016, 12th-14thSep. 2016, Zadar, Croatia, pp. 95 , 2016

22. Rajesh, M., and J. M. Gnanasekar. "An optimized congestion control and error management system for OCCEM." International Journal of Advanced Research in IT and Engineering 4.4 (2015): 1-10

23. S. H. Teay, C. Batunlu and A. Albarbar, "Smart Sensing System for Enhanceing The Reliability of Power Electronic Devices Used in Wind Turbines", International Journal on Smart Sensing and Intelligent Systems., VOL. 10, NO. 2, June 2017, pp. 407-424

24. T. Giitsidis, E. G. Karakasis, A. Gasteratos, G. Ch. Sirakoulis, "Human and fire detection from high altitude UAV images", 2015 23rd Euromicro International Conference on Parallel, Distributed, and Network-Based Processing, pp.311, 2015

25. U. M. Margarete Vasterling, "Challenges and Opportunities for UAV Borne Thermal Imaging",Thermal Infrared Remote Sensing, Netherlands, Springer, 2013, pp. 69-92

26. Wang, Da-Jinn, Yen-Hui Yin, and Tsong-Yi Chen. "Smoke Detection for Early Fire-Alarming System Based on Video Processing." Journal of Digital Information Management 6.2 (2008)

27. Wildfire Causes. Fire and Aviation Management, National Park Service U.S Department of Interior. Available at online: https://www.nps.gov/fire/wildland-fire/learning-center/fire-in-depth/wildfirecauses.cfm (accessed on 6 December 2017)

28. Yuan, C.; Liu, Z.; Zhang, Y. Aerial images-based forest fire detection for firefighting using optical remote sensing techniques and unmanned aerial vehicles. J. Intell. Robot Syst. 2017, 88, 635-654

29. Yuan, C.; Zhang, Y.; Liu, Z. A survey on technologies for automatic forest fire monitoring, detection, and fighting using unmanned aerial vehicles and remote sensing techniques. Can. J. For. Res. 2015, 45, 783-792. 